\title{
Claiming Public Health Crisis to Regulate Sexual Outlets: A Critique of the State of Utah's Declaration on Pornography
}

\author{
Kimberley McKay ${ }^{1} \cdot$ Christopher Poulin $^{1} \cdot$ Miguel Muñoz-Laboy ${ }^{2}$ (I)
}

Received: 30 July 2020 / Revised: 4 November 2020 / Accepted: 5 November 2020 / Published online: 30 November 2020

(c) Springer Science+Business Media, LLC, part of Springer Nature 2020

In constitutional democratic societies such as the U.S., elected officials in local, state, and federal governments theoretically represent the values of their constituencies. As elected officials, they are entrusted to provide leadership with the responsibility to generate public policy that will protect the rights and welfare of the people that they represent. This basic mandate is challenged, when elected officials generate policies based on moral values that do not necessarily represent those of their constituencies. In this Commentary, we will discuss the potential cultural and psychosocial impacts of the 2016 decision by the State of Utah's government to declare pornography a public health crisis.

\section{Brief Historical Perspective}

The history of governmental involvement in the management of sexuality through public health has been well documented by sexuality research historians (Foucault, 1990; Macleod \& Durrheim, 2002; McKee, 2009; Weeks, 2002, 2017). The American Public Health Association (2020) defines public health as promoting and protecting the health of people and the communities where they live, learn, work, and play; using research to identify risks of disease and injury; and acting to prevent them before they occur. In broad terms, the public health mandate is to understand the relationship between the spread of communicable, infectious diseases, and how the environmental conditions and personal choices affect the mechanisms by which they are transmitted (Walker, 1989). Evidence-based

Kimberley McKay

kimberly.mckay@temple.edu

1 School of Social Work, College of Public Health, Temple University, Bell Building, 1101 W. Montgomery Ave., Philadelphia, PA 19122, USA

2 Department of Community Health and Social Medicine, School of Medicine, City University of New York, New York, NY, USA public health policy, multi-level approaches, and community mobilization have facilitated the control of several communicable diseases and health conditions (APHA, 2020; Brownson, Baker, Deshpande, \& Gillespie, 2017). However, public health has also been used as a tool to further political agendas with limited concern for the control of disease. Authoritarian, morality-based public health policies not based on evidence, such as the United States Adolescent Family Life Act (AFLA), Community-Based Abstinence Education (CBAE), and Title V, Section 510 of the Personal Responsibility and Work Opportunity Reconciliation Act of 1996, became the foundation for the U.S. federal government to require abstinence only until marriage educational programs to the states in order to receive federal funding for sexuality education. The AFLA was not effective, and it caused unnecessary harms, behavioral risks, outbreaks of sexually transmitted infections, and psychological harms to young people nationwide (Lerner \& Hawkins, 2016; Santelli, 2017; Santelli et al., 2017; Smith, Panisch, Malespin, \& Pereira, 2017).

Our current understanding of the management of communicable diseases as well as non-communicable conditions, such as diabetes, cardiac disease, and substance use disorders, is strongly rooted in evidence-based, scientific practices designed to increase the health and well-being of the populations served by our local, state, and federal governments (Brownson et al., 2017). Thus, when the outbreak, spread, and/or lethality of communicable or non-communicable disease merits government intervention to protect the population, it is declared a public health crisis (e.g., the 2017 declaration of the opioid epidemic as a public health crisis or the 2020 public health crisis declaration of COVID-19) (HHS, 2019; White House United States of America, 2019, 2020). A public health crisis grants access to federal and state funding to address the declared issue through increased governmental actions including but not limited to law-enforcement, education, and healthcare services. 


\section{Pornography Does Not Meet the Definition of a Public Health Crisis}

The consumption of pornography, broadly defined as watching pornography and/or using pornography for self-sexual stimulation or masturbation, does not meet the definition of a communicable disease, i.e., the frequency of pornography usage cannot be transmitted through vectors, person-to-person or through environmental conditions such as influenza, dengue fever or chlamydia (Brownson et al., 2017). Pornography is also not a non-communicable condition. Chronic or acute non-communicable conditions can lead to health impairment, sudden death, and/or premature mortality (Brownson et al., 2017). Pornography use is not inherently addictive, with most users reporting no negative consequences, distress, or functional impairment (Hald \& Malamuth, 2008; McKee, Byron, Litsou, \& Ingham, 2020; Vaillancourt-Morel \& Bergeron, 2019; Vaillancourt-Morel et al., 2017; Willoughby, Busby, \& Young-Petersen, 2019; Willoughby, Carroll, Busby, \& Brown, 2016).

From a governmentality perspective, pornography in a sense is in the realm of the laws that regulate civism and human conduct. Pornography eludes a standardized definitive definition due to its highly subjective nature and has been a point of controversy for decades (McKee et al., 2020). Definitional interplay with artistic expressions protected by the U.S. First Amendment make legislation restricting the sale and consumption of pornography a legal matter (Hudson Jr., 2019). Individual perspectives about the moral values attached to sexually explicit material further complicate how policymakers and courts regulate the marketing and consumption of pornography. Some legal standings, however, have been drawn. In the 1982 US Supreme Court decision in New York versus Ferber, it was determined that the First Amendment provides no protection against consumption of sexually explicit depictions of minors (Case Law Studies, 1982). Since then, numerous laws have been approved that further restrict the distribution and ownership of sexually explicit material depicting minors (Hudson Jr., 2019). Beyond age as a legal standing for regulation of distribution and consumption of sexually explicit material, no other parameter exists. The nude adult human body is not in and of itself considered obscene by legal standards as per the 1974 US Supreme Court ruling Jenkins versus Georgia, but where that line is drawn still remains strongly subjective (Case Law Studies, 1974).

\section{Declaring Pornography as a Public Health Crisis}

On April 19, 2016, the State of Utah's Governor Gary Herbert signed resolutions S.C.R. 9 and H.B. 155. Resolution H.B. 155 focuses on the surveillance of what Utah state laws consider criminal behavior, thus reinforcing our perspective that the state's concern with pornography is in the realm of the law. H.B. 155 Reporting of Child Pornography focuses solely on reporting instances of child pornography. In summary, it requires computer technicians who find child pornography while working to report it to law enforcement or the federal Cyber Tip Line for child pornography. The full resolution is available at: https ://le.utah.gov/ 2016/bills/static/HB0155.html.

S.C.R. 9 Concurrent Resolution on the Public Health Crisis says pornography is a public health hazard leading to a "broad spectrum of individual and public health impacts and societal harms" and that the "pornography epidemic is harming the citizens of Utah and the nation." It also states that the use of pornography "can impact brain development and functioning, contribute to emotional and medical illnesses, shape deviant sexual arousal, and lead to difficulty in forming or maintaining intimate relationships," and that it "normalizes violence and abuse of women and children." The full resolution is available at: https://le.utah.gov/ 2016/bills/static/SCR009.html.

During the press conference after the signing of the S.C.R. 9 resolution, next to Utah's Governor Gary Herbert, Clay Olsen wore a t-shirt that said: "Porn Kills Love." Mr. Olsen is the cofounder and owner of the organization named "Fight The New Drug" referring to pornography (FightTheNewDrug, 2016). Different from H.B. 155, resolution S.C.R. 9 uses a public health platform to equate the consumption of pornography to the consumption of drugs, chemical dependence, and/or substance use disorders. It furthers points at pornography as the predictor of the social normalization of violence against women and genderbased sexual violence. Resolution S.C.R.9 is an authoritarian, morality-driven, not-evidence-based public health policy similar to the U.S. federal Abstinence Only education policy.

"Pornography addiction" is not a non-communicable, medical condition identified by the American Psychiatric Association, American Medical Association or the International Classification of Diseases (American Psychiatric Association, 2020; WHO, 2019). The American Association of Sexuality Educators, Counselors, and Therapists (AASECT) has weighed in on the issue, stating: "AASECT: (1) does not find sufficient empirical evidence to support the classification of sex addiction or pornography addiction as a mental health disorder, and (2) does not find the sexual addiction training and treatment methods and educational pedagogies to be adequately informed by accurate human sexuality knowledge" (Singal, 2016).

Similar to the Abstinence Only Education policy, Utah State's resolution S.C.R. 9 is likely to create unnecessary psychosocial distress around a non-existent diagnosis to adults within their legal rights to consume pornography. Individuals who legally consume pornography in the state of Utah are now subject to potential interpersonal stigmatization, the internalization of sex-negativity, and sexual shaming, all of which have been demonstrated 
to predict low-self-esteem, anxiety, depression, and substance use. This crisis-based language to public policy reinforces a moralistic approach to the consumption of pornography under the auspices of an otherwise scientifically credible public health authority, and is indicative of a regression to an earlier state of disease management that has been dissuaded by federal and state governments since it began adopting empirically based management approaches in the late 1800s. Because this declaration is not based on evidence, it creates a non-existent public health problem, "pornography addiction," de facto manufacturing a disease in the population in a way that is antithetical to the government's responsibility toward protecting the health of the people.

While the language of public health has been adopted by Utah's Governor Herbert to espouse the perceived dangers of pornography consumption, either in its 2017-2020 Strategic Plan, or in its 111 pages 2017-2020 Health Improvement Plan, the Utah State Department of Health makes no mention of addressing pornography consumption as a priority (Miner, 2017; Utah Department of Health, 2018). This disconnect between Governor Herbert and the actual Department of Health may be representative of simple latency between the generation and enactment of public policy. However, the almost three year gap between the governor's office and the state health department may suggest other motives outside the protection of the health of the people of Utah for resolution S.C.R. 9.

A study carried out in 2009 by the Harvard Business School showed that the state of Utah had the highest number of online adult entertainment subscriptions, per-capita, in the U.S. (Edelman, 2009). Prior to the S.C.R. 9 resolution and after the signing, there have been numerous mental health and psychological services offered to individuals and couples affected by pornography in the state of Utah. These services are provided by professional and non-professionally trained providers. For example, using the searching in Psychology Today, we identified 477 professional providers in the Salt Lake City metropolitan area of Utah, under the search term "pornography addiction" (PsychologyToday, 2020). The focus of this Commentary is not to criticize our colleagues in mental health services treating addictions or compulsive behaviors but rather the government's use of public health to legitimize non-existent medical conditions without even providing evidence-based treatment protocols.

\section{Adding to the Confusion: Forthcoming $6 \mathrm{C72}$ Compulsive Sexual Behavior Disorder}

The vast majority of the disorders defined by the DSM- 5 require not merely the presence of symptoms but the additional criteria of distress and/or impairment experienced by the individual (American Psychiatric Association, 2020). The World Health Organization agrees that marked distress must be present for the diagnosis of compulsive sexual behavior (WHO, 2019). The statement further clarifies that "distress that is entirely related to moral judgments and disapproval about sexual impulses, urges, or behaviors is not sufficient to meet this requirement."WHO's forthcoming compulsive sexual behavior disorder states that pornography is just one potential aspect of sexual compulsivity.

Vaillancourt-Morel and Bergeron (2019) stated that compulsive sexual behavior disorder could include pornography under the ICD-11 consideration by the WHO, but only when viewing pornography is objectively intense, repetitive, and a source of distress or functional impairment. The challenge in this position is the variability in defining what "objectively intense and repetitive" criteria are. We agree with Vaillancourt-Morel and Bergeron (2019) that "without objective indicators of selfperceived problematic pornography, the risk of pathologizing some sexual desires or fantasies without understanding and addressing the underlying context and issues is high" (p. 438). When pornography is declared as a devastating, health harming behavior, then there is a collective risk of pathologizing perfectly normal experiences. For example, when a 15-year-old youth who has not had a conversation about sex with one's parents and gets sent to a therapist because the youth was caught looking at pornography by the parent/s can cause unnecessary psychological distress to the youth.

Our interpretation of the WHO statement on pornography is not that the frequency of watching pornography itself causes psychological harm or dependence but rather when the behavior causes distress or impairment, such as the case for someone who jeopardizes their job by watching pornography during their lunch hour at work knowing that this behavior is in violation of the person's work policy. It is for someone who has a compulsion or impulses that are interfering with their daily life. The problem with these public health declarations is that it is a blanket statement that all pornography is detrimental, including the person who looks at it once a week at home.

The lack of linkages between Governor Herbert's use of the language of public health and Utah's State Department of Health leaves room for the question: Under what public health authority, for whom, and with what guidance has Governor Herbert pioneered his opposition to pornography? Uncovering the answer to this question is vitally important because the legitimization of "pornography addiction" and declaring pornography a public health crisis burden the mental health care system with additional patients with non-existent conditions. For example, if the emphasis of resolution S.C.R. 9 is to address the culture of violence against women, why not declare violence against women a public health crisis? S.R.C. 9 might potentially deviate future state-level mental health treatment resources from sex, family, and relationship professional therapists dealing with the treatment of well-documented clinical and social problems affecting their patient populations. 


\section{Implications}

Since 2016, 14 other states have made similar declarations of crisis following Utah's original denouncement of pornography (Coalition, 2019). While there is no clarity on the legal standing of resolution S.C.R. 9, nor are there funding provisions attached to these resolutions, the proliferation of restricting pornography policies seems motivated by political motives for state elections, re-elections, and/or the increase in pseudoscience organizations interested in profiting from pathologizing sexual expressions and sexual outlets.

Using the public health crisis claim to regulate pornography usage is conceptually inappropriate. The role of public health efforts should not be to stigmatize populations and create further stressors and distract from priority public health issues. While there is no doubt that the intentions behind said public policy are born from compassion, it is deeply important that this issue is tempered with evidence-based, empirical, scientific inquiry into the effects of pornography consumption.

Even if the perceived dangers of pornography stated in policies such as S.C.R. 9 (spousal conflict, sexual communication issues, divorce, relationship satisfaction, and so on) are at the core of these resolutions, pornography addiction, as defined in those statements, is not likely the cause. We reiterate that rather than creating distracting public health crisis resolutions, proclamations for investments in increasing access and equity to evidence-based mental health treatment and care services are bound to have sustainable, positive effects in the quality of life, sexual health, and mental health of individuals and families. Perhaps, for now, we should be reserving announcements about public health for the public health authorities.

Acknowledgements The content of this Commentary is solely the responsibility of the authors and does not necessarily represent the official views of Temple University's School of Social Work or the City University of New York's School of Medicine. The authors would like to thank Jeremy Irvin, Greg Langan, and Kathryn Leslie for their feedback and guidance on the initial versions of this Commentary.

\section{References}

American Psychiatric Association. (2020). Diagnostic and statistical manual of mental disorders (DSM-5). Retrieved July 20, 2020, from https://www.psychiatry.org/psychiatrists/practice/dsm.

American Public Health Association. (2020). Definition of public health. Retreived July 20, 2020 from https://www.apha.org/ what-is-public-health.

Brownson, R. C., Baker, E. A., Deshpande, A. D., \& Gillespie, K. N. (2017). Evidence-based public health. London: Oxford University Press.

Case Law Studies. (1974). JENKINS v. GEORGIA (1974) No. 73-557. Retrieved July 15, 2020, from https://caselaw.findlaw.com/ussupreme-court/418/153.html.
Case Law Studies. (1982). United States Supreme Court NEW YORK v. FERBER(1982) No. 81-55. Retrieved July 20, 2020, from https ://caselaw.findlaw.com/us-supreme-court/458/747.html.

Coalition. (2019). Public Health Crisis Resolution-National Decency Coalition. Retrieved January 20, 2020, from https://nationalde cencycoalition.org/updates/.

Edelman, B. (2009). Markets: Red light states: Who buys online adult entertainment? Journal of Economic Perspectives, 23(1), 209-220.

FightTheNewDrug. (2016). Fight the new drug. Retrieved July 15, 2020, from https://fightthenewdrug.org/our-team/.

Foucault, M. (1990). The history of sexuality: An introduction. New York: Vintage.

Hald, G. M., \& Malamuth, N. M. (2008). Self-perceived effects of pornography consumption. Archives of Sexual Behavior, 37(4), 614-625.

HHS. (2019). Opioids: The prescription drug \& heroin overdose epidemic. Retrieved July 15, 2020, from https://www.hhs.gov/opioi ds/.

Hudson Jr., D. (2019). Pornography and obscenity. Retrieved July 1, 2020, from https://www.freedomforuminstitute.org/first-amend ment-center/topics/freedom-of-speech-2/adult-entertainment/ pornography-obscenity/.

Lerner, J. E., \& Hawkins, R. L. (2016). Welfare, liberty, and security for all? U.S. Sex Education Policy and the 1996 title V Section 510 of the Social Security Act. Archives of Sexual Behavior, 45(5), 1027-1038. https://doi.org/10.1007/s10508-016-0731-5.

Macleod, C., \& Durrheim, K. (2002). Foucauldian feminism: The implications of governmentality. Journal for the Theory of Social Behaviour, 32(1), 41-60.

McKee, A., Byron, P., Litsou, K., \& Ingham, R. (2020). An interdisciplinary definition of pornography: Results from a global Delphi Panel [Technical Report]. Archives of Sexual Behavior, 49(3), 1085-1091. https://doi.org/10.1007/s10508-019-01554-4.

McKee, K. (2009). Post-Foucauldian governmentality: What does it offer critical social policy analysis? Critical Social Policy, 29(3), $465-486$.

Miner, J. (2017). Utah Department of Health Strategic Plan (1st ed.). Salt Lake City, UT: Utah Department of Health.

PsychologyToday. (2020). Finding therapists and counselors. Psychology Today. Retreived on June 15, 2020 from: https://www.psych ologytoday.com/us/therapists.

Santelli, J. (2017). Abstinence-only education doesn't work: We're still funding it. The Washington Post. Retrieved on May 15, 2020 from: https://www.washingtonpost.com/news/posteverything/ wp/2017/08/21/abstinence-only-education-doesnt-work-werestill-funding-it/.

Santelli, J. S., Kantor, L. M., Grilo, S. A., Speizer, I. S., Lindberg, L. D., Heitel, J., et al. (2017). Abstinence-only-until-marriage: An updated review of US policies and programs and their impact. Journal of Adolescent Health, 61(3), 273-280.

Singal, J. (2016). Experts: Sex and porn addiction probably aren't real mental disorders. The Cut. Retrieved from https://www.thecu t.com/2016/12/sex-and-porn-addiction-probably-arent-real-menta 1-disorders.html.

Smith, T. E., Panisch, L. S., Malespin, T., \& Pereira, M. G. (2017). Evaluating effectiveness of abstinence education. Journal of Evidence-Informed Social Work, 14(5), 360-367.

Utah Department of Health. (2018). Utah health improvement plan 2018 [Ebook]. Salt Lake City, UT: Utah Department of Health. Retrieved from https://ibis.health.utah.gov/ibisph-view/pdf/opha/ publication/UHIP.pdf.

Vaillancourt-Morel, M.-P., \& Bergeron, S. (2019). Self-perceived problematic pornography use: Beyond individual differences and religiosity. Archives of Sexual Behavior, 48(2), 437-441. 
Vaillancourt-Morel, M.-P., Blais-Lecours, S., Labadie, C., Bergeron, S., Sabourin, S., \& Godbout, N. (2017). Profiles of cyberpornography use and sexual well-being in adults. Journal of Sexual Medicine, 14(1), 78-85.

Walker, B. (1989). The future of public health: The Institute of Medicine's 1988 report. Journal of Public Health Policy, 10(1), 19-31.

Weeks, J. (2002). Sexuality and its discontents: Meanings, myths, and modern sexualities. London: Routledge.

Weeks, J. (2017). Sex, politics and society: The regulation of sexuality since 1800. London: Routledge.

White House United States of America. (2019). Ending America's opioid crisis. Retrieved July 15, 2020, from https://www.whitehouse .gov/opioids/.

White House United States of America. (2020). Proclamation on declaring a national emergency concerning the novel coronavirus disease (COVID-19) outbreak. Retrieved June 15, 2020, from https ://www.whitehouse.gov/presidential-actions/proclamation-decla ring-national-emergency-concerning-novel-coronavirus-diseasecovid-19-outbreak/.
WHO. (2019). 6C72 Compulsive sexual behaviour disorder-ICD-11 for Mortality and Morbidity Statistics (Version 04/2019). Retrieved July 15, 2020, from https://icd.who.int/browse11/1-m/en\#/ http\%3A\%2F\%2Fid.who.int\%2Ficd\%2Fentity\%2F1630268048

Willoughby, B. J., Busby, D. M., \& Young-Petersen, B. (2019). Understanding associations between personal definitions of pornography, using pornography, and depression. Sexuality Research and Social Policy, 16(3), 342-356.

Willoughby, B. J., Carroll, J. S., Busby, D. M., \& Brown, C. C. (2016). Differences in pornography use among couples: Associations with satisfaction, stability, and relationship processes. Archives of Sexual Behavior, 45(1), 145-158.

Publisher's Note Springer Nature remains neutral with regard to jurisdictional claims in published maps and institutional affiliations. 